\title{
Analysis of Unsafe Factors in Subway Operation
}

\author{
Nana Sun \\ Institute of economic management, Beijing Jiaotong University, Beijing 100044, China; \\ 15120576@bjtu.edu.cn
}

Keywords: Subway, Unsafe factors, Operations management, Security management.

\begin{abstract}
With the rapid development of urban infrastructure in china, the number of subway line opening and operation is increasing year by year, Subway operation management is also becoming more and more important. This paper analyzes the unsafe factors during the operation of the subway through the types of accidents that may occur in the subway operation, It includes four aspects: human factor, system factor, social environment and management factor. Finally, the paper puts forward three aspects to ensure the normal and efficient operation of the subway from the following aspects: establishing and improving the subway safety regulations, establishing and improving the emergency response plan system and improving the safety skills of the staff members. The unsafe factors in subway operation are analyzed, making management countermeasures, it is of great significance to improve the safety situation of metro operation and to prevent accidents.
\end{abstract}

\section{Introduction}

With the continuous development of social economy in our country, Urban traffic construction is also developing rapidly, at present, the subway has occupied an important position in the construction of urban traffic. Densely populated urban areas, heavy traffic pressure, so it is more important to speed up the construction of the subway. The operation of the subway is related to all aspects of the city, it is a huge and complex system engineering. Therefore, the analysis of the unsafe factors in the operation of the subway is to ensure the premise of safe operation. From the point of view of system theory, the unsafe factors of subway are classified into four categories, human, system, environment and management. Using management as a means of control and coordination, the coordination of people, systems, societies.

The main types of subway operation accidents fall into 4 categories[1-2]:

Table 1 Main types of subway operation accidents

\begin{tabular}{|c|l|}
\hline Type & \multicolumn{1}{c|}{ Reason } \\
\hline fire & $\begin{array}{l}\text { Security personnel negligence, passengers are prohibited from carrying alcohol, flammable, } \\
\text { explosive dangerous goods onto board, passengers sometimes fail to observe the safety } \\
\text { regulations for riding and smoke illegally, so that cigarette butts fall everywhere, leave a } \\
\text { safety hazard to the train. In addition, man-made explosions, terrorist attacks, arson are also } \\
\text { causes of fires }\end{array}$ \\
\hline $\begin{array}{c}\text { train } \\
\text { derailment or } \\
\text { collision }\end{array}$ & $\begin{array}{l}\text { the train derailment and collision is the unreasonable design of the subway line, can't meet } \\
\text { the specific conditions of the subway operation, at the same time, subway wiring equipment } \\
\text { becomes aging, accidents occur when the subway is speeding }\end{array}$ \\
\hline the stampede & the escalator failure, the elevator and other equipment are not reasonably protected \\
\hline $\begin{array}{c}\text { terrorist } \\
\text { attacks }\end{array}$ & $\begin{array}{l}\text { the subway is a relatively crowded place for people, If there are many people in the case of } \\
\text { security incidents, will have a huge influence, At the same time, the focus of terrorist attacks } \\
\text { is the subway }\end{array}$ \\
\hline
\end{tabular}




\section{Unsafe Factors in Subway Operation}

\subsection{Human Factors}

There are many factors affecting the safety operation of the subway in china, among them, the staff and managers have a large proportion of factors, China's subway safety operations, mainly through the operation of the relevant departments and professional staff to protect, therefore, the responsibility, the professional ability and the psychological quality of these staff members need strict requirements, once the technical level of the staff can't meet the operational needs, it is prone to security incidents, in addition, the personnel factors include the passengers themselves, in recent years, the relevant data of subway operation safety problems can be seen, for the subway traffic safety rules ignored by the increasing crowd, resulting in security incidents have occurred, therefore, it can be said that the main factor affecting the safety of subway accidents is human factors[3].

\subsection{System Factors}

In terms of efficiency, the subway is a relatively efficient means of transportation. However, during the operation of the subway, there will be some safety accidents due to its own reasons, such as train derailment, gate fault and mechanical fault and so on. Due to the number of train passengers, these problems will increase the harmfulness of the accident to some extent and cause great loss. Therefore, the subway company should regularly check and maintain the subway train, so as to prepare for the prevention of subway safety accidents. It can be seen that the problem of the train itself is an important factor influencing the safety of metro operation in China[4].

\subsection{Social Environment}

The subway operation is affected by environmental factors, mainly including internal and external environment, the internal environment is mainly concerned with the society and the working environment, and the human factors are also divided into the internal environment, the internal environment is mainly affected by the mental and emotional changes of the staff and passengers, the external environment is mainly for the impact of the natural environment to consider, from the point of view of earthquakes and climate, it is the external environmental factors that affect the safety of subway operation, from the social environment, China's economy and the establishment of relevant legal system may also have a certain impact on the safety of the subway operation.

\subsection{Management Factors}

Staff safety training is not enough, business ability assessment is not strict, staff security awareness is weak, so that some of the avoidable things happen frequently, if the power supply network fails because of improper maintenance, the signal system is not processed in time, resulting in poor train operation and so on. It is reported that in March 2017, Shanghai Subway Line 10 was in operation, door failure, in order to guarantee the continuation of line 10, the driver did not stop the door, and use staff to block the door, ensure the normal operation of the line. The door glitch should have been shut down for maintenance, but in the way that the staff kept the door open, if there is a slight difference, it will pay a heavy price. These are largely due to poor management of staff, which makes safety accidents frequent. 


\section{Strengthening Safety Management Measures of Subway Operation}

\subsection{Formulate and Improve the Subway Safety Regulations}

From the safety operation of urban subway in our country, making and complying with system standards is critical, In order to complete the safety management of subway projects, it must be formulated according to the relevant laws and regulations of the state, if there are no pertinent laws and regulations in a certain situation, it can be chosen by the industry standards of subway construction; The safety of subway projects should be related to the work of performance management content, the use of equipment is clearly defined, in the subway project, the safety management standard should be strictly followed and the scientific safety consciousness should be established; The relevant provisions of the subway safety management policy can be presented in written form to the staff in order to better accept the supervision of relevant units and passengers, in the application of safety management mode, the policy is the core content, and the review procedure which is to be guaranteed by the guideline is better applied to the safety management of subway engineering in China[5].

\subsection{Establish and Improve Emergency Plan System}

When planning the emergency plan for subway safety accidents, safety management personnel should seek advice and ideas from all aspects in light of the actual situation, Then the scientific and effective method is adopted to further demonstrate, thus improving the science and effectiveness of the emergency plan. Based on the actual situation, the emergency plan should be established and improved in a timely manner to improve the staff's awareness of safety and the ability to analyze and solve the hazard problem, more importantly, the emergency response plan which involves organize related department personnel security field exercise content, to ensure effective implementation of the emergency system and to effectively prevent security risks[6].

\subsection{Continuous Improvement of Staff Security Skills}

Urban subway staff in China should improve their comprehensive quality and technical level so as to prevent the occurrence of safety accidents effectively, at present, our city subway safety management is relatively lack of actual work experience of staff, therefore, in view of this situation, in order to ensure the safe operation of the subway company, need to pay attention to a large number of related professionals, to arrange training and education to the staff, constantly improve the technology level of the staff, so as to enhance the safety prevention knowledge and awareness, in addition to the staff should also ask its moral quality meet the requirements, avoid because of the sense of responsibility is not strong cause safety problem, security problem during the subway at the same time to strengthen the skills competition through the use of forms, you can also to the corresponding security drills, constantly improve the staff in the face of the security issues when processing capacity[7].

\section{Conclusion}

Subway as a means of transportation for the masses, convenient and fast, is its advantages, however, China's subway business started relatively late, and there are still many problems in operation and management, which need us to solve, especially the subway operation safety management. The masses took the subway in order to arrive at their destination in a convenient and timely manner, if the subway operation Department in the safety management, due to neglect of management, causing major accidents, will bring serious consequences to the state, society and 
enterprises. The state attaches great importance to the safe operation of urban rail transit, and clearly proposes to gradually build a safe, convenient and sustainable urban rail transportation mode to better serve the public. Therefore, we should pay more attention to the management of the subway, to ensure the effective operation of the subway, it is necessary to formulate and improve the subway safety rules and regulations, establish and perfect the emergency response plan system, and continuously improve the safety skills of staff. From these three aspects, we can guarantee the normal and efficient operation of the subway.

\section{References}

[1] Li Bei, Guo Shanbin. Study on subway operation accidents and countermeasures [J]. enterprise technology development, 2016,35 (03): 59-60.

[2] Wang Yan. Mechanism analysis and Countermeasures of Subway stampede accident [D]. Beijing Jiaotong University, 2015.

[3] Li Zhenshan. Discussion on subway operation safety management mode [J]. Theoretical research on urban construction (electronic version), 2017, (07): 109+113.

[4] Ma Yu. Analysis of unsafe factors and Management Countermeasures in subway operation management [J/OL]. China high technology enterprises, 2017, (01): 102-103.

[5] He Ming, Wang Xu. Study on subway operation safety management countermeasures [J]. Transportation enterprise management, 2012, (11): 65-67.

[6] Kuang Weilin. About the safety management of subway operation countermeasures [J]. City construction theory research (Electronic Edition), 2017, (19): 174-175.

[7] Yan. Shiwei. subway safety management problems and improvement measures[J]. Small and medium-sized enterprise management and Technology (the magazine),2014 (01): 158-159. 